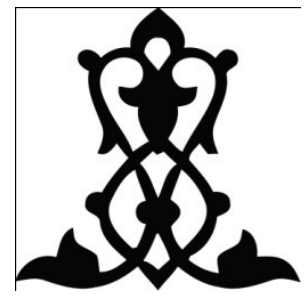

\title{
AKTIVITAS SITOTOKSIK SENYAWA METABOLIT SEKUNDER KAPANG ENDOFIT Evodia suaveolens DENGAN METODE BSLT (Brine Shrimp Lethality Test)
}

\author{
Azmi Azhari \\ Jurusan Pendidikan IPA Biologi,FITK, IAIN Syekh Nurjati Cirebon \\ azmi.biochemist@gmail.com
}

\begin{abstract}
Abstrak
Kanker adalah penyakit degeneratif dengan kasus yang makin meningkat setiap tahunnya. Menurut WHO (World Health Organization) (2003) kasus kanker dunia diprediksi akan mengalami peningkatan 50\% menjadi 15 juta kasus pada tahun 2020. Oleh sebab itu, diperlukan obat antikanker yang mencukupi kebutuhan dan juga efektif. Evodia suaveolens atau Zodia adalah tanaman khas Indonesia timur yang diketahuimengandung suatu senyawaantikakner yaitu evodiamin. Evodiamin yang dihasilkan dari Zodia tidaklah banyak sehingga diperlukan inovasi baru.Pemanfaatan kapang endofit yang diisolasi dari Evodia suaveolens diharapkan dapat menjadi solusi produksi Evodiamin yang kurang efektif dari tanamannya langsung. Produksi senyawa dengan mikroorganisme akan lebih cepat daripada produksi dengan organisme multiseluler dan potensi industri skala massalnya terbuka. Kapang endofit yang tumbuh dari suatu jaringan tanaman akan lebih dari satu jenis kapang, maka perlu ada uji screening awal untuk memilih kapang terbaik, salah satunya adalah denga metode BSLT. Isolasi kapang endofit dari batang Evodia suaveolens menghasilkan 8 isolat. Nilai $L C_{50}$ dari masing-masing kapang endofit adalah kapang 1 memiliki nilai 315 ppm, kapang 3 memiliki nilai 270 ppm, kapang 5 memiliki nilai 400 ppm, kapang 7 memiliki nilai 19.7 ppm dan kapang 8 memiliki nilai 403 ppm. Nilai ini membuktikan konsentrasi tersebut dapat membunuh populasi Artemia salina sebanyak $50 \%$.
\end{abstract}

\section{PENDAHULUAN}

Kanker merupakan penyakit degeneratif yang mematikan. Menurut WHO (World Health Organization) (2003) kasus kanker dunia diprediksi akan mengalami peningkatan 50\% menjadi 15 juta kasus pada tahun 2020. Sebagian besar penyakit kanker disebabkan oleh lingkungan dan gaya hidup. Faktor 
lingkungan yang menyebabkan kanker antara lain polusi, asap rokok, radiasi, dan infeksi organisme. Faktor gaya hidup yaitu kebiasaan merokok, konsumsi alkohol, makanan yang mengandung bahan tambahan pangan yang karsinogenik,dan makanan berlemak trans serta obesitas. (Jemal 2011). Teknologi untuk terapi kanker seperti pembedahan, radiasi, terapi hormon dan kemoterapi banyak dikembangkan saat ini, namun pengobatan ini memerlukan biaya yang mahal dan memiliki efek samping yang tidak baik bagi tubuh, untuk itu perlu dikembangkan suatu pengobatan yang dapat mengobati kanker dengan kemampuan mengobati yang kuat dan tanpa efek samping.

Indonesia merupakan negara yang memiliki kekayaan alam yang sangat melimpah. Kekayaan sumber tanaman herbal yang beragam, memiliki potensi obat yang besar, salah satunya adalah anti kanker. Tanaman yang memiliki potensi anti kanker adalah tanaman zodia (evodia suaveolens). Zodia merupakan tanaman asli daerah irian (papua) (Kardinan 2007), tanaman ini biasa digunakan untuk mengusir nyamuk, dengan cara menggosokkan daunnya ke kulit. Studi terbaru membuktikan bahwa kandungan senyawa evodiamin dari zodia mempunyai aktivitas yang baik sebagai anti kanker. Senyawa aktif evodiamin dapatmenghambat proliferation, invasion, metastasis dan mempercepat apoptosis beragam sel kanker (Jiang 2009). Namun pengembangan obat yang berbahan dasar zodia masih menghadapi kendala, senyawa aktif yang diperoleh dari tanaman zodia tidaklah banyak, sehingga diperlukan tanaman yang banyak untuk mendapatkan senyawa tersebut. Terbatasnya sumber daya alam, dan waktu tumbuh tanaman yang lama membuat efisiensi produksi obat ini menjadi turun.

Pengembangan teknologi produksi senyawa aktif dari tanaman obat merupakan teknologi yang memiliki prospek yang baik. Salah satu bioteknologi yang dapat digunakan untuk menghasilkan senyawa obat dalam skala besar adalah dengan menggunakan metabolit sekunder yang diekstrak dari kapang endofit. Penggunaan kapang endofit dapat meningkatkan efisiensi produksi senyawa anti kanker, masa berkembangbiak kapang endofit yang relatif singkat dengan laju pertumbuhan yang tinggi memungkinkan produksi senyawa anti kanker semakin efisien dalam jumlah besar.

Senyawa bioaktif antikanker yang akan digunakan untuk produk antikanker harus diujikan terlebih dahulu dengan uji sitotoksik. Uji sitotoksik merupakan salah satu pengembangan metode untuk memprediksi keberadaan senyawa yang bersifat toksik pada sel (Kurnijasanti et al. 2008). Salah satu metode uji sitotosisitas adalah Brine Shrimp Lethality Test (BSLT) yang dapat digunakan 
untuk praskrining terhadap senyawa-senyawa yang diduga berkhasiat sebagai anti tumor (Sukardiman et al. 2004 dalam Widyastuti 2008)

Penelitian ini akan menggunakan fraksi murni ekstrak kapang endofit yang diisolaisi dari daun Zodia. Perlakuan dengan menggunakan fraksi ini akan diuji dengan menggunakan beberapa perlakuan dosis untuk mendapatkan hasil induksi yang lebih efektif sehingga dapat mendorong pengembangan tanaman Zodia sebagai produk fitofarmaka khususnya dalam upaya terapi pengobatan penyakit kanker. Diharapkan dengan penelitian ini dapat memberikan manfaat dalam pemenuhan kebutuhan senyawa anti kanker yang murah dan memiliki aktivitas yang tinggi, serta dapat menjadi rujukan bagi industri farmasi Indonesia untuk memproduksi senyawa bioaktif dalam skala besar.

\section{METODOLOGI}

Penelitian ini terdiri dari 5 tahapan, yaitu isolasi dan pemurnian kapang endofit, peremajaan kapang endofit, fermentasi, ekstraksi senyawa metabolit sekunder, dan uji toksisitas dengan menggunakan BSLT (Brine Shrimp Lethality Test) dengan menggunakan $\mathrm{LC}_{50}$.

\section{Isolasi dan pemurnian kapang endofit}

Batang tanaman Evodia suaveolensdengan panjang $2 \mathrm{~cm}$ dan lebar $1 \mathrm{~cm}$ dicuci dengan air mengalir, lalu disterilkan dengan etanol 70\% selama 1 menit, natrium hipoklorit 5,3\% selama 5 menit, dan etanol 75\% selama 0,5 menit. Bagian batang dibelah dua secara longitudinal, lalu diletakkan di atas cawan petri berisi PDA yang telah dicampur dengan kloramfenikol $0,05 \mathrm{mg} / \mathrm{mL}$ (Theantana et al. 2007). Keduanya diinkubasi selama 3 hari pada suhu $25^{\circ} \mathrm{C}$, kemudian koloni dipindahkan ke PDA dalam cawan petri dan selanjutnya diinkubasi lagi pada suhu $25^{\circ} \mathrm{C}$ dan dilakukan pengecekan secara berkala untuk pemurnian lebih lanjut. Masing-masing endofit diisolasi melalui beberapa kali ditanam pada agar miring (PDA) dan diinkubasi dalam inkubator suhu $25^{\circ} \mathrm{C}$, selanjutnya setiap 3 bulan sekali diremajakan kembali. Sebagian isolat mikroba endofit disimpan dalam medium PDA pada suhu $-80^{\circ} \mathrm{C}$

\section{Peremajaan Kapang Endofit dari Isolat (Pelczar dan Chan 2008)}

Inokulasi isolat kapang endofit dilakukan secara aseptis di dalam laminar. Laminar terlebih dahulu disterilkan dengan penyinaran sinar ultraviolet selama 1 
jam kemudian seluruh bagian dalam laminar dan bagian luar kaca disemprot dengan etanol teknis. Isolat kapang endofit dari agar miring diinokulasi ke dalam media PDA kemudian diinkubasi selama dua hari pada suhu kamar.

\section{Fermentasi Kapang Endofit (Modifikasi Kumala dan Muhamad 2008)}

Isolat kapang yang telah diremajakan masing-masing diinokulasikan ke dalam tabung Erlenmeyer berisi $50 \mathrm{ml}$ media PDB. Tiap tabung Erlenmeyer difementasi dengan metode statik pada suhu kamar selama 12 hari. Metode selanjutnya akan diekstrak dengan kloroform.

\section{Ekstraksi Metabolit Sekunder (Kumala dan Muhamad 2008)}

Tiap bagian diekstrak dengan pelarut masing-masing sebanyak tiga kali ekstrak dan pada tiap ekstraksi digunakan pelarut sebanyak $50 \mathrm{ml}$. Fase pelarut ditampung dalam botol yang telah diketahui bobot kosongnya. Hasil ekstraksi diuapkan dibawah kipas angin hingga tertinggal residunya. Bobot ekstrak diperoleh dari selisih antara bobot botol kosong dan bobot botol berisi ekstrak. Ekstrak didalam botol dipindahkan ke vial yang lebih kecil dengan dilarutkan terlebih dahulu dengan pelarutnya. Untuk membantu melarutkan kerak yang tertinggal, digunakan alat sonikator.

\section{UJI BSLT (Brine Shrimp Lethality Test) (Meyer et al 1982)}

Telur udang Artemia salina L sebanyak 1 sudip dilrutkan dalam 250 $\mathrm{ml}$ air laur dalam sebuah labu Erlenmeyer, dimasukan aerator, dan didiamkan selama 1×24 jam agar menjadi larva udang. Selanjutnya disampakan larutan sampel dengan konsentrasi masing-masing 500 ppm, 100 ppm, 50 ppm, dan 10 ppm. Perhitungan larva yang masih hidup dan yang mati dilakukan setelah 24 jam untuk menentukan nilai $\mathrm{LC}_{50}$.

\section{HASIL DAN PEMBAHASAN}

Kapang endofit adalah kapang yang hidup pada tumbuhan, dan bersifat menguntungkan (saprofit) bagi inangnya. Kapang endofit yang digunakan berasal dari batang Zodia. Tahapan pertama adalah proses isolasi. Tujuan utama dari tahapan ini adalah untuk mengisolasi kapang yang ada di dalam batang Zodia tersebut.

Penelitian ini dimulai dengan pencucian batang Zodia dengan dialirkan air 
selama 10 menit untuk menghilangkan kotoran. Setelah itu, batang dipotong, dilakukan sterilisasi dan diletakkan pada media PDA (Potatos Dextrose Agar) yang telah dibuat. Proses sterilisasi berurutan dengan menggunakan etanol, sodium hipoklorit $(\mathrm{NaOCl})$, dan etanol dengan perbandingan waktu pencelupan 1:5:0.5 menit. Hal ini dimaksudkan untuk membunuh kapang dan bakteri yang berasal dari permukaan batang, sehingga yang diisolasi hanya kapang yang berasal dari jaringan tanaman. PDA sebelumnya telah ditambahkan dengan kloramfenikol dengan tujuan sebagai antibakteri. Setelah itu, media PDA berisi batang tanaman diinkubasi selama 1-2 minggu.

Banyaknya isolat yang akan dihasilkan bergantung pada media yang digunakan. Penggunaan media yang berbeda akan menghasilkan kekayaan spesies yang berbeda. Pada tahapan isolasi ini dihasilkan kapang isolat sebanyak 8 kapang yang disajikan pada gambar 1.

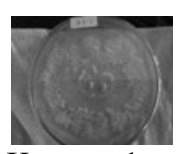

Kapang 1

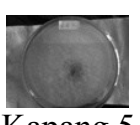

Kapang 5

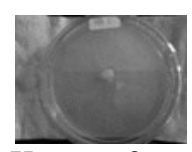

Kapang 2

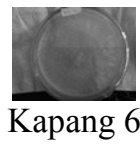

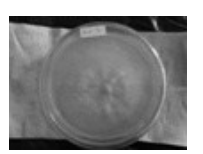

Kapang 3

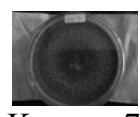

Kapang 7

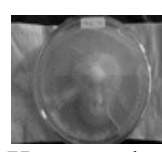

Kapang 4

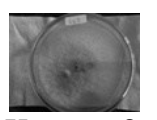

Kapang 8

Gambar 1 Isolat kapang endofit Evodia suaveolens

Tahapan kedua adalah proses fermentasi. Proses ini bertujuan untuk menumbuhkan dan menghasilkan produk senyawa metabolit sekunder. Isolat yang dihasilkan, ditumbuhkan lagi pada media PDB (Potato Dextrose Broth) yang telah disterilisasi. Setelah itu, dilakukan fermentasi selama 12 hari pada suhu ruang yang dilakukan dengan statis. Adapun maksud dilakukannya fermentasi statis adalah agar senyawa yang dihasilkan lebih banyak. Namun, fermentasi dinamis tetap dilakukan dengan maksud untuk mengetahui perbandingan hasil metabolit sekunder yang dihasilkan. Fermentasi dinamis dilakukan pada suhu $28^{\circ} \mathrm{C}$ dengan agitasi $170 \mathrm{rpm}$. Setelah fermentasi, dilakukan ekstraksi dengan menggunakan kloroform dengan tujuan mengekstrak senyawa alkaloid yaitu evodiamin (Winarno 2006).

Pada tabel 1 diperlihatkan bobot residu hasil ekstrak dari kloroform yang telah diuapkan. 
Tabel 1 Bobot Ekstrak Kloroform dari Kapang Endofit Evodia suaveolens.

\begin{tabular}{lll}
\hline $\begin{array}{l}\text { Nomor } \\
\text { Kapang }\end{array}$ & $\begin{array}{l}\text { Bobot } \\
\text { Ekstrak } \\
\text { (Gram) } \\
\text { Fermentasi } \\
\text { Dinamis }\end{array}$ & $\begin{array}{l}\text { Bobot } \\
\text { Ekstrak } \\
\text { (Gram) } \\
\text { Fermentasi } \\
\text { Statis }\end{array}$ \\
\hline Kapang 1 & 0.03 & 0.41 \\
Kapang 2 & 0.03 & 0.21 \\
Kapang 3 & 0.02 & 0.10 \\
Kapang 4 & 0.02 & 0.11 \\
Kapang 5 & 0.03 & 0.06 \\
Kapang 6 & 0.03 & 0.05 \\
Kapang 7 & 0.03 & 0.08 \\
Kapang 8 & 0.02 & 0.10 \\
\hline
\end{tabular}

Dari tabel diatas, diperlihatkan pada fermentasi statis hasil yang diperoleh lebih banyak dari pada fermentasi dinamis.Produksi dengan fermentasi statis lebih banyak dibandingkan dinamis, disebabkan kemungkinan produk digunakan kembali oleh kapang tersebut.

Tahapan yang terakhir dilakukan adalah pengujian dengan menggunakan metode BSLT (Brine Shrimp Lethality Test) dengan menguji LC $_{50}$. Tujuan utama dari tahapan ini adalah untuk mengetahui konsentrasi yang dapat membunuh dari setengah populasi Artemia salina.Nilai tersebut menggambarkan bioaktifitas metabolit yang dihasilkan. Semakin kecil nilai konsentrasi yang dapat membunuh setengah populasi larva maka akan semakin tinggi bioaktivitasnya, begitu pula sebaliknya. Pada uji ini akan dipilih kapang yang memiliki bioaktivitas yang terbaik.

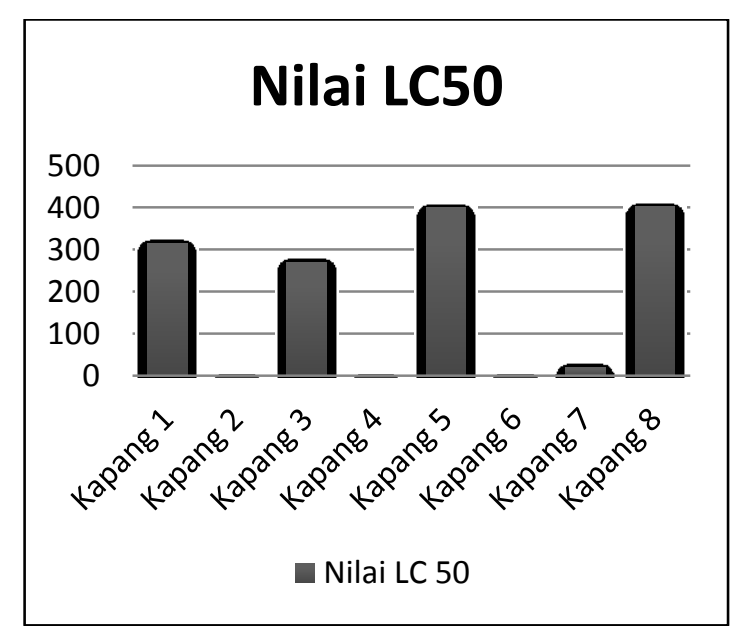

Gambar 2 Aktivitas Sitotoksik dari isolat kapang endofit Evodia suaveolens. 
Dari gambar 2 diperlihatkan bahwa kapang 1 memiliki nilai 315 ppm, kapang 3 memiliki nilai 270 ppm, kapang 5 memiliki nilai 400 ppm, kapang 7 memiliki nilai 19.7 ppm dan kapang 8 memiliki nilai 403 ppm. Nilai tersebut menunjukan konsentrasi yang dapat membunuh dari setengah populasi Artemia salina. Sedangkan untuk kapang 2, kapang 4, dan kapang 6 tidak memiliki bioaktifitas dan daya toksik pada konsentrasi 500, 100, 50 dan 10 ppm. Kemungkinan kapang 2, 4, 6 daya bioaktif diatas 500 ppm. Kapang yang memiliki bioaktivitas tertinggi terdapat pada kapang 7. Kapang ini diperkirakan mempunyai aktivitas sitotoksik yang cukup tinggi dan dapat diuji untuk tahapan selanjutnya,

\section{SIMPULAN DAN SARAN}

Isolasi kapang endofit dari batang Evodia suaveolens menghasilkan 8 isolat. Aktivitas sitotoksik tertinggi terdapat pada kapang 7. Penelitian ini perlu dilanjutkan dengan penelitian lanjutan untuk menguji lebih lanjut senyawa yang dihasilkan dari kapang tersebut dan aktivitas terhadap sel kanker. Dengan adanya penelitian ini, diharapkan senyawa antikanker dapat diproduksi lebih murahdan memenuhi kebutuhan.

\section{DAFTAR PUSTAKA}

Jemal A, Bray F, Center MM, Ferlay J, Ward E, Forman D . 2011. Global cancer statistics. CA: a cancer journal for clinicians61 (2): 69-90.

Jiang, J, Hu, C. 2009.Evodiamin: A Novel Anti-Cancer Alkaloid from Evodia rutaecarpa. Molecules 14, 1852-1859

Kardinan, Agus. 2007. Tanaman Pengusir Dan Pembasmi Nyamuk. Agromedia Pustaka. Jakarta.

Kumala Shirly, Muhammad Gembong. 2005. Isolasi dan Penapisan Kapang Endofit Tanaman Secang (Caesalpinia sappan L.) sebagai Penghasil Senyawa Antibakteri. MEDICINUS(Scientific Journal of Pharmaceutical Development and Medical Application) $21: 15$ [terhubung berkala] http://lib.atmajaya.ac.id/default.aspx?tabID $=61 \& \mathrm{id}=129265 \& \mathrm{src}=\mathrm{a} \quad[28$ September 2011]. 
Kurnijasanti Rochmah, Hamid Iwan Sahrial, Rahmawati Kadek. 2008. Efek Sitotoksis in vitro dari Ekstrak Buah Mahkota Dewa (Phaleria macrocarpa) terhadap Kultur Sel Kanker Mieloma. J. Penelit. Med. Eksakta 7 ( 1) : 48-54.

Mayer, A., Gustafson, K. 2008. "Marine Pharmacology in 2005-2006: Antitumour and Cytotoxic Compounds". EuropeanJournal Of Cancer 44 ( 2008 ) 2357-2387

Melliawati et al. 2006. Pengkajian Bakteri Endofit Penghasil Senyawa Bioaktif untuk Proteksi Tanaman. Biodiversitas 7(3): 221-224.

Meyer BN et al. 1982. Brine shrimp: a convenient general bioassay for active plants constituent. J Medical Plant Res 45:31-34.

Michael lam. 2003. Beating cancer with natural medicine.bloomington: USA.

Pelczar JR, Han ES. 1996. Dasar-dasar Mikrobiologi. Jakarta: UI Pr.

Theantana T., K.O. Hyde and S. Lurnyong. 2007. Asparaginase production by endophytic fungi isolated from some thai medical plants. KMITL Science Technology· Joumc; $\sim$ L 7 (1): 13-18

Widyastuti, Shanti. 2008. Uji Toksisitas Ekstrak Daun Iprih (Ficus glabella Blume) terhadap Artemia salina Leach dan Profil Kromatografi Lapis Tipis. Jurusan Farmasi Universitas Muhamadiyah Surakarta

Winarno EK. 2006.Produksi Alkaloid oleh Mikroba Endofit yang Diisolasi dari Batang Kina Cinchona Ledgeriana Moens dan Cinchona Pubescens Vahl (Rubiaceae). Jurnal Kimia Indonesia. (2):8-15 